\title{
Psychosis and OCD with Urge for Gannibalism: Manifestations of Mesial Temporal Selerosis
}

Hiranya Kumar Goswami, Dhrubajyoti Bhuyan, Neha Dua

Department of Psychiatry, Assam Medical College, Dibrugarh, Assam, India.

Abstract:

Psychiatric disorders can be associated with seizure disorder as comorbidity or they can be secondary to structural lesions in the brain. Patients with temporal lobe epilepsy frequently come to the attention of psychiatrists since the condition may involve gross disorders of thought and emotion. Here we will discuss about a case of mesial temporal sclerosis presenting with 6 years seizure and recent onset psychosis (delusion disorder) and $O C D$ with an urge for cannibalism. Patient achieved an excellent response with carbamazepine, fluvoxamine and low dose risperidone.

Key words: Seizures, Psychotic disorders, Cannibalism, Epilepsy, Delusions, Carbamazepine.

\section{Introduction}

Psychiatric problems associated with seizures are a concern to both psychiatrists and neurologists [1] and in general, psychiatric problems are greater in temporal lobe epilepsy (80\%) [2]. Indeed, misdiagnosis and failures of diagnosis are common in temporal lobe epilepsy (TLE) and distinction is important because abnormality of behaviour during a temporal lobe seizure may occur in the absence of generalized grand mal seizure. Physicians may often fail to recognize the epileptic origin of the disorder and these issues should be addressed especially for management purpose. Here we will discuss about a case mesial temporal sclerosis presenting with 6 years seizure and recent onset psychosis and $O C D$ with an urge for cannibalism. Patient achieved an excellent response with carbamazepine, fluvoxamine and low dose risperidone.

\section{Case Report}

Mr. X, 49 years old, male educated up to BA, was admitted in department of Psychiatry, Assam Medical College, Dibrugarh with a 15 days history of repeated thoughts and urge to eat his son, wife and raw chicken liver. On further enquiry as reported by the wife, 6 years ago he had severe headache, recurrent jerky and abnormal movements of the whole body along with loss of consciousness. CT scan brain, EEG, routine blood examination, ECG and chest $\mathrm{X}$-ray did not reveal any abnormality at that time. After few days he started showing episodic headache, dizziness, flushing of face, tingling sensations of limbs, uneasiness in stomach, following which he would have over-religious behaviour, crying episodes, irrelevant talk, suspiciousness and even feelings of sexual excitement lasting for 15-20 minutes. He

Corresponding Author: Dr. Dhrubajyoti Bhuyan

Email: dr.dhrubajyoti@gmail.com

Received: November 29, 2014 | Accepted: March 10, 2015 | Published Online: April 10, 2015

This is an Open Access article distributed under the terms of the Creative Commons Attribution License (creativecommons.org/licenses/by/3.0)

Conflict of interest: None declared | Source of funding: Nil | DOI: http://dx.doi.org/10.17659/01.2015.0038 
could recognize people during the episode and could recall most if not all of the episode. During few episodes he had sudden starring look, became motionless and had tightening of limbs lasting for 2-3 minutes along with loss of consciousness. In between the episodes he was asymptomatic with mild headache occasionally. For 3 years he took leviteracetam $1000 \mathrm{mg}$, tablet divalproate sodium $500 \mathrm{mg}$ in two divided doses regularly. With these medicines as only frequency of episodes decreased to one in 6 months following which he stopped taking the medication. Thus Mr. X, reported to have a 6-year history of poorly controlled seizures.

In last two months the frequency of such episodes had increased to one episode at two days interval and at times 2-3 episodes in a day. In one such episode three weeks before admission he cut his finger and drank his blood and in another, he tried to hang himself with a rope. Since 15 days, he also got persistent repeated urges and thought to eat his son and asked his wife to shift the son to a relative's place otherwise he would eat him. These thoughts would increase during the episodic seizure if he had any or whenever he would think about the child or someone talked about the child. To stop him from eating his son he would lock himself inside a room, jump, shout, cry and bang his head on wall. He also started having low mood and suspecting that all this is because of the magic done by his previous wife because she wants to destroy his family. His personal care, work function and social interaction decreased. One day secondary to his urge to eat raw meat he ate the raw liver of hen with blood following which he felt happy, satisfied without any feelings of disgust. Then he also started to get thoughts and urges to eat the wife and other people also.

There was no significant past and family history of mental illness or major physical illness or head injury. Personal history concerning birth or febrile convulsions could not be elicited. His first wife had eloped and now he is married again since
5 years and has a 4 years old son. Patient is also a very occasional user of alcohol with last intake 2 months ago. Premorbidly patient had anxious personality traits. MSE revealed anxious effect, delusion of persecution - mainly directed towards the first wife, obsessive thoughts, impulses and controlling compulsion with intact judgement and grade III insight. One episode of seizure occurred during the hospital stay following which he was investigated further.

$M R$ imaging of brain showed focal areas of FLAIR hyper-intensities in head and proximal body of left hippocampus with normal appearance of distal body and tail region without significant volume loss suggestive of mesial temporal lobe sclerosis. EEG, routine blood examinations, chest $X$-ray, ECG were normal. After detailed workup he was diagnosed to be a case of seizure disorder due to mesial temporal lobe epilepsy (MTLE) with psychosis (delusion disorder) and comorbid obsessive compulsive disorder.

Patient was started on tablet carbamazepine $400 \mathrm{mg}$ in two divided doses, tablet risperidone 1 $\mathrm{mg}$ at bed time gradually increased to risperidone $2 \mathrm{mg}$ and trihexiphenydyl $2 \mathrm{mg}$ combination 1 tablet at bed time, tablet fluvoxamine $50 \mathrm{mg}$ once daily in morning increased to $100 \mathrm{mg}$ a day after a week, clonazepam $0.5 \mathrm{mg}$ at bed time along with tablet methylcobalamine and pantaprazole. Patient started to show improvement and there was marked decrease in intensity of symptoms like thoughts to eat his wife and child. He started to talk to child over phone everyday without any urge of eating him. After he was seizure free for one week and clinical improvement patient was discharged on carbamazepine $1000 \mathrm{mg}$ in divided doses, fluvoxamine $150 \mathrm{mg}$, risperidone $2 \mathrm{mg}$ and trihexiphenydyl $2 \mathrm{mg}$ combination 1 tablet at bet time, clonazepam $0.5 \mathrm{mg}$ at bed time, along with methylcobalamine. Till last follow up, patient was maintaining well with resuming of normal duties. 


\section{Discussion}

Temporal lobe epilepsy (TLE) accounts for around $60 \%$ of all patients with localisation related epilepsy. The most frequent cause of TLE is hippocampal sclerosis, also known as mesial temporal sclerosis. Temporal lobe seizures may take the form of simple and complex partial seizures, with both occurring in some $70 \%$ of patients [3]. High-resolution MRI can detect the characteristic hippocampal sclerosis that appears to be essential in the pathophysiology of MTLE for many patients [4].

Auras produced in temporal lobe seizures are most complex and varied of all and highly characteristic. They often contain elements that echo symptoms seen in psychiatric disorder because of which they are of special interest to the psychiatrist [5]. The epigastric aura is the most common, being reported by up to $50 \%$ of patients with TLE cephalic aura by $23 \%-30 \%$ patients and anxiety/fear by $14 \%-24 \%$, somatosensory by 2\%-19\% [6]. Biraben et al. 2001 [7] had talked about behavioural features that accompany intense ictal fear, which may include a call for help, marked agitation or frightened immobility. Our patient also had a varied aura everytime before the onset of abnormal behaviour. He had uneasy sensations rising from the epigastrium towards the throat, felt ballooning of epigastrium with butterfly sensation, had feeling of nervousness along with odd sensations in the head, dizziness, headache (cephalic aura), flushing of face, tingling sensation of limbs accompanied by anxiety, and intense ictal fear.

Seizures arising in the temporal lobes characteristically have a gradual onset, usually a motionless stare and are relatively prolonged, with automatisms often continuing for 2 minutes or occasionally even longer. Our patients during some ictus phase had motionless stare with tightening of body and loss of consciousness and in some ictus phase had wandering, over religious, searching behaviour, irrelevant talk, suspiciousness along with lighting of incense. The presence of the ictal speech is suggestive of the onset in the non-dominant hemisphere. External emotive or behavioural manifestations such as anger, sadness, elation, circumstantiality, viscosity and hyper moralism are a result of right temporal foci. By contrast, left hemisphere foci cause's ruminative, intellectual tendencies such as religiosity, philosophical interest and a sense of personal destiny [8]. Our patient had left temporal lobe foci.

The etiology of MTS is still not fully understood. MTS is not only the cause of seizures, but clinical evidence suggests that MTS can also be the result of seizures [9]. However, postictal or anoxic hippocampal damage is generally bilateral. Infiltrating gliomas cause enlargement instead of volume loss of hippocampus and there was no evidence of cortical dysplasia. Therefore, these diagnoses were excluded in our patient.

The lifelong prevalence of all psychotic disorders among epileptic patients ranges from 7 to 12 percent [10]. Shukla et al. [11] found a significantly higher incidence of psychosis in patients with TLE compared to generalized epilepsy. Our patient also had a delusion. Association of a leftsided focus with psychosis is suggested by studies on the laterality of the seizure focus but it is still open to criticism [10].

A prominent link has been seen between temporal lobe (usually refractory) epilepsy (TLE) and OCD. Of TLE patients, $10 \%$ to $22 \%$ of patients may have OCD, often underdiagnosed in the outpatient clinic. Obsessive qualities of washing, symmetry/exactness, and ordering, with a greater preoccupation with certain aspects of religion, have been noted in TLE patients compared with controls or patients with idiopathic generalized epilepsy [12]. Ertekin and colleagues found that about $10 \%$ 
of TLE patients had OCD, $24 \%$ had subsyndromal OCD [13]. Our patient also had repeated thoughts and urges to eat his son and a controlling compulsion strong enough to diagnose the patient as having comorbid OCD. A psychic aura is "forced thinking" characterized by recurrent intrusive thoughts, ideas, or crowding of thoughts. Forced thinking must be distinguished from obsessional thoughts and compulsive urges. Epileptic patients with forced thinking experience their thoughts as stereotypical, out-of-context, brief, and irrational, but not necessarily as ego dystonic [10]. Our patient as persistent thoughts not only as a part of aura and also they were egodystonic, so forced thinking can be ruled out in our patient.

\section{Conclusion}

Distinction of symptoms is needed for effective management of a patient with MTLS. While epilepsy may be treated by physicians and neurologists, many of whom may remain unfamiliar with and even uninterested in its neuropsychiatric components. But by ignoring the experiential symptoms, they may deprive the patient of the opportunity to coherently integrate all aspects of the epilepsy. For effective management and improving quality of life of a patient with temporal lobe epilepsy (mesial temporal sclerosis) a close collaboration between psychiatrist and neurologist is needed.

\section{References}

1. Marchetti RL, Tavares AG, Gronich G. Complete remission of epileptic psychosis after temporal lobectomy: case report. Arq Neuropsiquiatr. $2001 ; 59: 802-805$.

2. Perini Gl, Tosin C, Carraro C. Interictal mood and personality disorders in temporal lobe epilepsy and juvenile myoclonic epilepsy. I Neurol Neurosurg Psychiatry. 1996;61:601-605.

3. Janszky J, Schulz R, Ebner A. Simple partial seizures (isolated auras) in medial temporal lobe epilepsy. Seizure. 2004;1 3:247-249.

4. Fauci AS, Kasper DL, Longo DL, Braunwald E, Hauser SL, Jameson JL, et al. Diseases of Central Nervous System-Seizures and Epilepsy. In: Harrison's-Principles of Internal Medicine, 17th ed. United States of America: Mc Graw Hill Medical: 2008; pp.3251-3269.

5. Mellers JDC. Epilepsy. In: David AS, Fleminger S, Kopelman MD, Lovestone S, Mellers JDC. Lishman's-Organic Psychiatry-A Textbook of Neuropsychiatry, $4^{\text {th }}$ ed. A John Wiley \& Sons Ltd: 2009; pp. 309-387.

6. Henkel A, Noachtar S, Pfander M, Luders HO. The localizing value of the abdominal aura and its evolution: a study in focal epilepsies. Neurology. 2002;58:271-276.

7. Biraben A, Taussig D, Thomas P. Fear as the main feature of epileptic seizures. Journal of Neurology, Neurosurgery and Psychiatry. $2001 ; 70 ; 186-191$.

8. Bear DM, Fedio P. Quantitative analysis of interictal behavior in temporal lobe epilepsy. Arch Neurol. 1977;34:454-467.

9. Spiegel R, Lee EY. Left mesial temporal sclerosis. Applied Radiol. 2004 ;33:6.

10. Mendez MF. Neuropsychiatric Aspects of Epilepsy. In: Sadock BJ, Sadock VA, Ruiz P. (eds) Kaplan and Sadock's textbook of psychiatryVol 2. $9^{\text {th }}$ ed. Lippincott Williams \& Wilkins: 2009; pp. 452-463.

11. Shukla GD, Srivastava ON, Katiyar BC. Psychiatric manifestations in temporal lobe epilepsy: a controlled study. $\mathrm{Br} J$ Psychiatry. 1979;135:411-417.

12. Kaplan PW. Epilepsy and obsessive-compulsive disorder. Dialogues Clin Neurosci. 201 0;1 2:241 248.

13. Ertekin BA, Kulaksizoglu IB, Ertekin E, Gurses C, Bebek N, Gokyigit A, et al. A comparative study of obsessive-compulsive disorder and other psychiatric comorbidities in patients with temporal lobe epilepsy and idiopathic generalized epilepsy. Epilepsy Behav. 2009;1 4:634-639. 